\title{
On Construction and Practice of Library Resources and Service Support Platform oriented to Key Discipline Construction
}

\author{
Xinyu Wang, Qingsong Zhang \\ library, \\ JiLin Agricultural University , \\ Changchun, China \\ Email: wangxinyu8303@126.com; Email: 1007738301@qq.com
}

Keywords: subject service; Web2.0; subject service platform; higher vocational college library

\begin{abstract}
Along with the development of information technology and the reinforcement of subject construction in higher colleges, higher college libraries should innovate on service models to carry out subject services. This paper analyses the necessities of subject service carried out by higher college libraries, and discusses the construction of subject service platform in higher college libraries.
\end{abstract}

\section{Introduction}

With the rapid development of college professional disciplines, teaching and research work put forward new requirements on the access to high-quality subject information, which are obviously unable to be satisfied by traditional discipline service of low flexibility. The introduction and development of subject librarian system, subject navigation, information gateway services and other discipline services alleviate the problem to some extent. However, it is necessary to find a more effective way for the current domestic service discipline is not yet mature and the service levels and quality are uneven. The good network environment, advanced network technology and the rapid development of information construction and knowledge-building provide resources and technical support for the implement of a centralized information system. The promotion of the construction and application of discipline service platform can provide a wide operating platform for librarian. Users can also be provided with convenient use and good discipline service and it is expected to improve the service level of library discipline.

\section{Problems existing in the progression of disciplinary services of university library}

The so-called "service discipline" is to organize a number of librarians who are good at book information knowledge and possess strong information retrieval organizational skills and with the background of established school professional subject knowledge as subject specialist to provide in-depth information service work for readers of a subject. The main content of discipline service includes: First, strengthen communication and contact between the library and faculty. Second, provide in-depth documentation services for the subject so that libraries can provide more direct and more targeted service for school teaching and research activities. Although the disciplinary services of domestic university library have achieved some success, the changes of internal and external environment such as changes oriented to service model and service content and the increasing updating rate of knowledge and technology bring new dilemma for disciplinary service. First of all, the information processing and service means are backward and the deep level intelligence and information service ability are incapable of satisfying the in-depth research and information needs of university teachers and students ${ }^{[1]}$. Secondly, the boundaries between librarians and users are too distinct and they lack interaction with each other. The business exchanges among users and 
librarians are not enough. Thirdly, because of the limitations of technological condition, the librarians and users are short of powerful tools to integrate electronic resources and the work platform to integrate service means. Fourthly, the lack of effective evaluation and incentives and the incapability to show the subject librarians' achievements lead to their lack of enthusiasm, persistence and initiative. The subject knowledge is slow to update and the narrow vision is hardly to keep up with the speed of the development of the subject and cannot guarantee the sustained development and progressive of discipline services.

\section{Necessity and reality of the construction of the platform of disciplinary services of university library}

With the acceleration of university disciplinary construction and the tremendous changes in people information demand, traditional discipline services have been difficult to meet people's needs. Therefore, it is urgent to find new service ways to resolve this impasse. The new disciplinary service represented by discipline service platform came into being and provided a feasible way to promote the sustained development of higher education and the development of library knowledge service $^{[2]}$. For universities, to concentrate all resources to fully support the construction of a discipline of high level and to promote scientific research and teaching centering on key disciplines can improve the overall scientific research strength and teaching level and lay the hardware foundation for building first-class universities. Here, the all resources include the stable, efficient, and high-quality information resources support provided by library knowledge services. On the one hand, university library shoulders the important mission of the school curriculum construction which must conduct the construction of information resources around the school disciplines construction and provide guidance and help for users' research. On the other hand, it also faces enormous changes in knowledge services such as resource development around the user needs and the evaluation of service levels by means of users' use efficiency. To solve these problems, university library must integrate the existing resources and change the service mechanism to build a centralized and interactive service center. It is naturally successful to build a subject service platform which integrates the professional discipline service teams of rich resources and information resources sharing and creation and other characteristics by combining the experience of previous discipline librarians, digital library, and other disciplines. It can be said that subject service platform is both the trend of times and the chance for universities to upgrade and develop sustainably. University library should seize the opportunity to actively implement measures and early finish the construction of disciplinary service platform which adapts to the school specialty and possesses a sound service capability ${ }^{[3]}$.

\section{The construction of the platform of disciplinary services of university library}

By combining with the characteristics and trends of university library discipline services, the author constructed the discipline services platform in line with the requirements of university library, which consists of four parts: disciplinary service resource module, disciplinary service function module, discipline platform management and expansion module.

\section{A. Disciplinary service resource module}

The disciplinary resource module is integrated by various types of discipline resources, including the collection of books, foreign language databases, e-books, image resources, audio and video resources and network resources, etc. The document types include books, journals, newspapers, conference papers, theses, patents, standards, etc. In this module, user can find all types of subject resources anytime and have timely access to the latest scientific and research trends. For the convenience of users to find resources, this module also sets the search function to retrieve relevant resources within the platform and return to the user in the form of list. For the convenience of users, the search results can be presented in a more abundant form such as cover record, catalog, summary, brief introduction of author, reference, user reviews, content labels and other information 
to better screen ${ }^{[4]}$.

\section{B. Disciplinary service function module}

The disciplinary service function module is embodied discipline services, including discipline consulting services, SDI service, project tracking, discipline resource push, special database construction, subject information literacy education, etc. Discipline consulting services can provide answers to specific questions for users and provide instant help for users to solve the problem through good interactive. SDI service is targeted to get access to subject information resources aiming for user-specific discipline information needs. Project tracking refers to the integration of librarians into the user's subjects and the specialized information services provided from research program, topic research to project closure. Discipline resource push is to deliver the customized discipline information to the user's desktop through corresponding software such as RSS for the users' convenience to learn about the latest subject information. Special database construction is the thematic databases formed though the subject librarians' collection, screening, and integration of subject-related information resources. Users can get access to all information related to the topic in special database. Subject information literacy education means that subject librarians train users in the service platform. Generally speaking, online courses will be adopted for users' training and guidance.

\section{Discipline platform management module}

Discipline platform management module consists of user management and librarian management. User management module is that users can set customized information and a number of personalization features in the disciplinary service platform, which is similar to the function of CNKI personal digital library. System management is the set to the function module of disciplinary service platform and the updating and maintenance of the contents of each module. Background management is the monitoring and management on the quality of service including usage statistics, $\log$ analysis, and so on.

\section{Expansion module.}

Expansion module is a specific module. The so-called module means that the modules in the disciplinary service platform should be scalable and integrate more new features and elements with an open mind. With the development of web2.0 technology, some of its applications can also be added to the disciplinary service platforms, such as blog, wikis, RSS, tags, SNS and so on. The participation of scalable resources and services in the disciplinary service platform can make the platform more user-friendly, more diverse, and more able to meet the various needs of users. Meanwhile, the disciplinary service platform should take into account the application of embedded services, such as discipline consulting services can be embedded into each page of the platform, which is convenient for users to communicate with librarians anytime in the platform ${ }^{[5]}$. The disciplinary service platform is not an isolated platform and it should be compatible with other functional modules of library web site. This seamless and transparent approach to service can provide users with a better experience, but also makes the library service functions into a whole.

\section{Conclusion}

The disciplinary service platform of university libraries aiming for the construction of key disciplines is close to user needs, allowing users get access to the information they need conveniently, fast, and simply. It also improves the disciplinary service capacity and level of library. However, the construction and optimization of the disciplinary service platform of university libraries is not an overnight thing which needs to continue to absorb new technology and learn from the advanced experience. Keep improving and upgrading and construct the disciplinary service platform which is developed simultaneously with discipline and of obvious characteristics. 


\section{Acknowledgements}

This paper is the research finding of the 12th Five Year Plan of education science in Jilin Province "The construction and practice of support platform of universities' library rescourse and service facing to the construction of key disciplines" in the year of 2015 (Item Number: GH150212) and the research project of National Agricultural Literature Information Center of CALIS "The deep integration and further research of the library resources under the background of Big Data” in the year of 2015 (Item Number: 2015019)

\section{References}

[1] Zhou Juan. The design of the disciplinary service platform of university libraries aiming for service. [J] Tu Shu Guan Lun Tan, 2011 (31): 88-90.

[2] Yang Hualing. Study of the construction of the disciplinary service platform of university libraries based on SNS. [J]. Library and Information, 2012 (3): 104-106.

[3] Li Honglian. Research and analysis on the current situation of disciplinary service of university libraries. [J] Journal of Library Science, 2013 (8).

[4] Peng Li, Zeng Yongmei, Gan Wenzhi. On the design and implementation of one-stop disciplinary service platform based on Moodle. [J]. Journal of The Library Science Society of Sichuan, 2013 (3): 54-57.

[5] Kang Jian, Li Nan. Study of the construction of the disciplinary service network platform of domestic university libraries----- A Case Study of Library of East China University of Technology. [J] Library and Information, 2010 (6): 89-93. 